\title{
Spatial versus object visualizers: A new characterization of visual cognitive style
}

\author{
MARIA KOZHEVNIKOV \\ Rutgers University, Newark, New Jersey \\ and \\ STEPHEN KOSSLYN and JENNIFER SHEPHARD \\ Harvard University, Cambridge, Massachusetts
}

\begin{abstract}
The visual system processes object properties (such as shape and color) and spatial properties (such as location and spatial relations) in distinct systems, and neuropsychological evidence reveals that mental imagery respects this distinction. The findings reported in this article demonstrate that verbalizers typically perform at an intermediate level on imagery tasks, whereas visualizers can be divided into two groups. Specifically, scores on spatial and object imagery tasks, along with a visualizer-verbalizer cognitive style questionnaire, identified a group of visualizers who scored poorly on spatial imagery tasks but excelled on object imagery tasks. In contrast, a second group of visualizers scored high on spatial imagery tasks but poorly on object imagery tasks. The results also indicate that object visualizers encode and process images holistically, as a single perceptual unit, whereas spatial visualizers generate and process images analytically, part by part. In addition, we found that scientists and engineers excel in spatial imagery and prefer spatial strategies, whereas visual artists excel in object imagery and prefer object-based strategies.
\end{abstract}

A cognitive style is a psychological dimension that represents consistencies in how an individual acquires and processes information (Ausburn \& Ausburn, 1978; Messick, 1984). Researchers have proposed a wide variety of cognitive style dimensions (e.g., Keefe, 1979; Messick, 1976). Some styles are conceptualized as typical responses to particular stimuli, and other styles are regarded as cognitive principles that underlie complex behavior. Although there have been many studies of cognitive styles, most of them were not motivated by a theory or general framework that specifies the dimensions upon which cognitive processing may vary. As a consequence, much of the previous work suffered from arbitrary distinctions and overlapping dimensions. Thus, it is not surprising that only a few of these dimensions continue to generate research, such as field dependence-independence (Witkin, Moore, Goodenough, \& Cox, 1977), reflection-impulsivity (Messer, 1976), and the visualizer-verbalizer dimension (Kirby, Moore, \& Shofield, 1988; Paivio, 1971; A. Richardson, 1977; Riding \& Cheema, 1991). We focus on this last dimension in the present article.

This research was supported by the National Science Foundation under Grant REC-0106760. We thank Jason Tajima, Marie Burrage, and Jennifer Walsh for helping to implement the tests and conduct the studies. We also thank Marija Petkovic, Olessia Blajenkova, and Michael Motes for their help in conducting and analyzing the studies with members of different professions. Correspondence concerning this article should be addressed to M. Kozhevnikov, Psychology Department, Rutgers University, 101 Warren Street, 333 Smith Hall, Newark, NJ 07102 (e-mail: maria@psychology.rutgers.edu).
Bartlett (1932), Paivio (1971), and A. Richardson (1977) were among the first to propose that individuals can be reliably classified as visualizers versus verbalizers. According to this view, visualizers (also called imagers) rely primarily on imagery when attempting to perform cognitive tasks, whereas verbalizers rely primarily on verbalanalytical strategies. Some researchers have suggested that visualizers are expected to be more field independent and holistic, whereas verbalizers are more field dependent and analytic (e.g., Kirby et al., 1988). A major challenge for visualizer-verbalizer cognitive style research has been to devise methods and instruments to assess the dimension accurately. Paivio (1971) was the first to design an individual differences questionnaire with which to evaluate the extent to which different people habitually use imagery versus verbal thinking. This questionnaire asked participants to indicate whether or not each of a list of statements, such as "I often use mental pictures to solve the problems," described their habitual method of thinking. However, factor analyses on the responses given to the individual items identified not only imagery and verbal factors, but also a number of more specific factors (Paivio \& Harshman, 1983). Moreover, men tended to score high on items that related to the use of imagery in problem solving and in imagining moving objects, whereas women tended to score high on items that related to the use of imagery in remembering and generating mental images of previously perceived scenes. In an attempt to improve Paivio's questionnaire, A. Richardson selected 15 of its most discriminative items 
and composed a Verbalizer-Visualizer Questionnaire. However, Verbalizer-Visualizer Questionnaire scores proved to be only weakly related to the vividness of experienced imagery and to be essentially unrelated to scores on visual-spatial tasks (e.g., Alesandrini, 1981; Green \& Schroeder, 1990).

At the end of the 1970s, research on the visualizerverbalizer cognitive style dimension began to appear in the educational literature. On the basis of clinical methods, Krutetskii (1976) proposed that individuals can be classified into groups according to how they process mathematical information. The first group, the analytic type, consists of people who prefer verbal-logical modes when attempting to solve problems. The second group, the geometric type, consists of those who prefer to use imagery. Following Krutetskii's approach, Moses (1980), Suwarsono (described in Lean \& Clements, 1981), and Presmeg (1986a, 1986b) proposed that individuals can be placed on a continuum that specifies their preferences for using imagery while solving mathematical problems. Suwarsono developed the Mathematical Processing Instrument (MPI; described in Lean \& Clements, 1981) to measure an individual's degree of visuality, which is the tendency to use visual imagery when solving math problems. The questionnaire included a number of simple mathematics problems that could be solved by either visual or analytical methods. However, its validity was questioned because researchers failed to find a clear relationship between the degree of visuality and students' performance on either mathematical or spatial ability tests (Lean \& Clements, 1981).

Indeed, a host of studies have challenged the validity of the visualizer-verbalizer dimension. Although the verbal subscale of the Verbalizer-Visualizer Questionnaire is related to verbal ability measures (e.g., Green \& Schroeder, 1990; Kirby et al., 1988), the visual subscale is only weakly related to ratings of the vividness of mental imagery and is not even moderately related to other visual-spatial aptitude measures (e.g., Alesandrini, 1981; Edwards \& Wilkins, 1981; Green \& Schroeder, 1990). A moderate correlation between the visual subscale of the Verbalizer-Visualizer Questionnaire and spatial visualization ability was reported by Kirby et al., (1988), but only when all the items related to dream vividness were excluded from the questionnaire. Such findings cast doubt on the usefulness of the visualizer-verbalizer distinction, and interest in this dimension has declined over the past decade. In addition, the visualizer-verbalizer dimension, like other cognitive style dimensions, suffers from the fact that it is not rooted in a more general theory of human information processing. Instead, the distinction is based on intuition and anecdotal observations.

In this article, we describe a new approach to characterizing individual differences in cognitive functioning, which grows out of a key distinction about information processing - namely, the distinction between processing object properties and processing spatial relations. This processing distinction is rooted in the brain: Neuro- psychological data provide evidence that higher level visual areas of the brain are divided into two functionally and anatomically distinct pathways: the object and the spatial relations pathways (Haxby et al., 1991; Kosslyn \& Koenig, 1992; Ungerleider \& Mishkin, 1982). The object pathway runs from the occipital lobe down to the inferior temporal lobe and has been called the ventral system; this system processes properties of objects, such as shape and color. The spatial relations pathway runs from the occipital lobe up to the posterior parietal lobe and has been called the dorsal system; this system processes object localization and spatial attributes and is also essential for guiding movements.

The distinction between perceptual processing of object properties versus spatial relations extends to visual mental imagery (e.g., Farah, Hammond, Levine, \& Calvanio, 1988; Levine, Warach, \& Farah, 1985; Milner \& Goodale, 1995). For example, Levine et al. demonstrated that lesions in the temporal cortex disrupted performance of tasks that relied on mental images of objects and their properties, whereas such lesions did not disrupt spatial imagery; in contrast, lesions in the posterior parietal cortex had the reverse effects (see also Farah et al., 1988). Similarly, in neuroimaging studies, spatial and object imagery tasks led to very different patterns of brain activity (Kosslyn, Ganis, \& Thompson, 2001). For example, when participants visualized a route on a map that they had memorized prior to the experiment, the parietal lobes were activated; but when participants visualized faces or colors, the temporal lobes were activated (Uhl, Goldenberg, Lang, \& Lindinger, 1990). Moreover, Kosslyn and Anderson (summarized in Kosslyn, 1994, chap. 9) found that the more complex the pattern, the more time required to form an image of it using spatial imagery; in contrast, if one encoded the pattern as a single perceptual unit and later visualized it using object imagery, the time to create the image did not depend on image complexity.

The distinction between spatial and object imagery is also supported by findings of gender differences. Males have performed better than females on a variety of spatial orientation and mental rotation tasks (Collins \& Kimura, 1997; Geary, Gilger, \& Elliot-Miller, 1992; Kail, Carter, \& Pellegrino, 1979), whereas females have scored higher than males on imagery vividness questionnaires (e.g., Campos \& Sueiro, 1993). Consistent with these findings, Paivio and Clark (1991) showed that men could generate dynamic images more quickly than women could, but that women could generate static images more quickly than men could. Moreover, the distinction between object and spatial imagery appears to characterize individual differences. Kirby et al. (1988) found two visual factors in several of their factor analyses: one related to spatial visualization (i.e., the ability to manipulate and transform complex spatial images) and the other related to vividness of imagery - in particular, to dream imagery. Hegarty and Kozhevnikov (1999) found that the visual-spatial representations used by elementary school children while solving mathematical problems can be re- 
liably classified as primarily spatial or primarily pictorial; some of the children consistently used schematic spatial representations, and some preferred to use objectbased pictorial representations. Hegarty and Kozhevnikov also showed that preference for spatial representations is associated with both high spatial visualization ability and better performance on mathematics problem solving. Furthermore, they found that the use of spatial representations in problem solving is negatively correlated with the use of pictorial representations. Aginsky, Harris, Rensink, and Beusmans (1997) reported a similar dissociation between visual-object versus spatial strategies in wayfinding tasks. They found that some participants based their wayfinding decisions on visually recognized landmarks along a route, whereas others represented the environment as a survey map from the start.

Critically, Kozhevnikov, Hegarty, and Mayer (2002) found that although the majority of verbalizers they tested had average spatial ability, visualizers fell into two contrasting groups: those who had high spatial ability and those who had low spatial ability, with only a small number of visualizers having average spatial ability. Kozhevnikov et al. showed that visualizers who had high spatial ability tended to generate schematic abstract images when interpreting science graphs, whereas visualizers who had low spatial ability tended to generate detailed pictorial images of individual objects.

The focus of this article is to develop a new approach to the visualizer-verbalizer cognitive style dimension. Unlike all previous efforts to characterize the visualizerverbalizer cognitive style, we reject the idea that imagery can be characterized as variation along a single dimension. We argue, instead, that there are in fact two distinct types of visual cognitive style, reflecting different ways of generating mental images and processing visual-spatial information. Specifically, we predict that some people are especially good in constructing vivid, pictorial, and detailed images of individual objects, whereas other people excel in creating images that represent spatial relations among objects and in imagining spatial transformations.

In Studies 1 and 2, we examined the performance of visualizers and verbalizers on different imagery tasks. If there are two qualitatively different types of visualizers, we would expect to find a bimodal distribution, with some excelling at spatial imagery and some excelling at object imagery. We would expect no such distribution among the verbalizers, but instead, we would expect a normal distribution of verbalizers' scores across all imagery tasks. In Study 3, we compared the performance of visualizers and verbalizers on general and verbal intelligence tests. Study 4 focused on systematic differences in imagery abilities for people engaged in different types of professional activities - in particular, visual arts versus science and engineering. We hypothesized that scientists and engineers should have excellent spatial imagery and prefer spatial strategies, but visual artists should have excellent object imagery and prefer object imagery strategies.

\section{STUDY 1}

In this study, we administered a test that was intended to assess spatial imagery (the mental Paper Folding Test, or PFT), a questionnaire that was intended to survey objectbased imagery (the Vividness of Visual Imagery Questionnaire, or VVIQ), and a Visualizer-Verbalizer Cognitive Style instrument modeled after an instrument used in the educational literature to distinguish verbalizers from visualizers. If, in fact, there are two types of visualizers and these styles are qualitatively distinct, people who score high on the spatial-based imagery task should not score high on the object imagery questionnaire, and vice versa.

\section{Method}

Participants. One hundred sixty-two participants took part in Study 1 . This group consisted of 116 paid volunteers ( 56 males and 60 females), 18-40 years of age, recruited through sign-up sheets posted around the Harvard University campus, and 46 volunteers (21 males and 25 females), recruited from the psychology participant pool at Rutgers University at Newark, as well as through signup sheets posted around the Rutgers campus.

Materials. The materials consisted of a pretest questionnaire, which included questions about the student's age and gender, the Visualizer-Verbalizer Cognitive Style Questionnaire, the PFT, and the VVIQ.

Visualizer-Verbalizer Cognitive Style Questionnaire. The purpose of this questionnaire was to measure the participants' preference for using imagery, as opposed to verbal-logical strategies, when solving problems. The Visualizer-Verbalizer Cognitive Style Questionnaire includes 11 mathematical problems, selected from the MPI, ${ }^{1}$ and has been used in previous studies to distinguish between visualizers and verbalizers (Kozhevnikov et al., 2002; Lean \& Clements, 1981; Presmeg, 1986a, 1986b); specifically, the problems were taken from, or modeled after, those of Suwarsono (described in Lean \& Clements, 1981). As in previous measures of the visualizer-verbalizer cognitive style dimension (Lean \& Clements, 1981), this test included two parts. Part I contained 11 written mathematics problems that can be solved by either visual or nonvisual methods (see examples of the problems in Appendix A). A pilot study determined that these problems were challenging but not too difficult for the students and that the participants used a variety of strategies to solve them. Part II contained descriptions of the most common ways of solving the problems in Part I (identified from prior interviews with students about how they solved these problems; e.g., Kozhevnikov et al., 2002; Lean \& Clements, 1981). In Part II, the participants were asked to indicate the strategy they had used for each problem. Space was provided for individuals to describe alternative methods that were not listed. We assigned a score of 2 for any visual solution or combination of visual solutions checked by the students, a score of 0 for any nonvisual solution (irrespective of whether the answer to the problem was correct or incorrect), and the intermediate score of 1 for a combination of verbal and visual methods. The internal reliability (alpha-Cronbach) of the questionnaire was .80 .

Paper Folding Test. According to Ekstrom, French, and Harman (1976), the PFT measures spatial visualization ability, which reflects the ability to apprehend, encode, and mentally manipulate abstract spatial forms (Lohman, 1988). Researchers (e.g., Poltrock \& Agnoli, 1986; Poltrock \& Brown, 1984) have shown that scores on tests of spatial visualization ability are related to how well people can rotate and integrate imaged forms and, essentially, are not re- 
Table 1

Mean Scores and Standard Deviations for the Paper Folding Test (PFT; Out of a Total Possible Score of 10) and the Vividness of Visual Imagery Questionnaire (VVIQ; out of 80) as a Function of Cognitive Style

\begin{tabular}{lccccc}
\hline & \multicolumn{2}{c}{ Visualizers } & & \multicolumn{2}{c}{ Verbalizers } \\
\cline { 2 - 3 } \cline { 5 - 6 } Test & $M$ & $S D$ & & $M$ & $S D$ \\
\hline PFT & 6.49 & 2.34 & & 6.27 & 2.21 \\
VVIQ & 63.10 & 9.86 & & 60.65 & 8.81 \\
\hline
\end{tabular}

lated to participants' ability to generate vivid or detailed visual images. The participants were administered Part I of the PFT, which consists of 10 items. Each item showed successive drawings of two or three folds made in a square sheet of paper. The final drawing showed a hole being punched in the folded paper. The participant selected one of five drawings to indicate what the punched sheet would look like when fully opened. The internal reliability of the PFT was .84 (Ekstrom et al., 1976). Examples of items from the PFT are provided in Appendix B.

The total score for the PFT was calculated using a correction for guessing, according to the formula $R-W /(n-1)$, where $R=$ the number of correct items, $W=$ the number of incorrect items, and $n=$ the number of response options for each item ( $n=5$ for the PFT).

Vividness of Visual Imagery Questionnaire. The VVIQ (Marks, 1972 ) is the most frequently used measure of how vividly individuals can form visual mental images. The VVIQ consisted of 16 items for which the participants rated, on a 5-point scale, the vividness of mental images they were asked to create. Typical items were, "The sun is rising above the horizon into a hazy sky" and "A strong wind blows on the trees and on the lake, causing waves." The internal reliability of the questionnaire was .88 .

Procedure. All the participants were tested individually. They were administered a pretest questionnaire, the Visualizer-Verbalizer Cognitive Style Questionnaire, the PFT, and the VVIQ. The order of these measures was counterbalanced. The participants were given only $3 \mathrm{~min}$ for the PFT; there were no time limits for the other measures.

\section{Results and Discussion}

We classified all the participants as either visualizers $(n=83)$ or verbalizers $(n=79)$ on the basis of a median split of their score on the Visualizer-Verbalizer Cognitive Style Questionnaire. ${ }^{2}$ Descriptive statistics for each of the variables we assessed are provided in Table 1 as a function of cognitive style. The mean score on the cognitive style questionnaire was $7.50(S D=2.12)$ for verbalizers and $13.47(S D=2.32)$ for visualizers. There was only a marginal difference between visualizers and verbalizers on the VVIQ $\left[F(1,161)=3.10, M S_{\mathrm{e}}=87.783, p=\right.$ $.08]$ and no hint of a difference on the PFT $[F(1,161)<$ 1]. The correlation between the VVIQ and the PFT was negative and marginally significant $(r=-0.14, p=$ .07). Scores on the Visualizer-Verbalizer Cognitive Style Questionnaire did not correlate significantly with those on the PFT ( $r=.03, p=.97)$ or the VVIQ ( $r=$ $.09, p=.24)$. Thus, when all visualizers are treated as the same, the results are consistent with previous research that did not show correlations between measures of visualizer versus verbalizer style and performance on visual-spatial tasks (e.g., Alesandrini, 1981; Edwards \& Wilkins, 1981; Green \& Schroeder, 1990; Lean \& Clements, 1981).

In order to differentiate between two types of visualizers, we grouped the participants with respect to their spatial imagery ability as follows: low (scores in the bottom $33.3 \%$ of the distribution on the PFT), intermediate (scores in the middle 33.3\%), or high (scores in the top $33.3 \%$ ). A median split would not have allowed us to identify the participants who scored unusually high or low, as compared with intermediate levels, as is essential in order to test the present hypothesis. Figure 1 presents the number of visualizers versus verbalizers who scored low, inter-

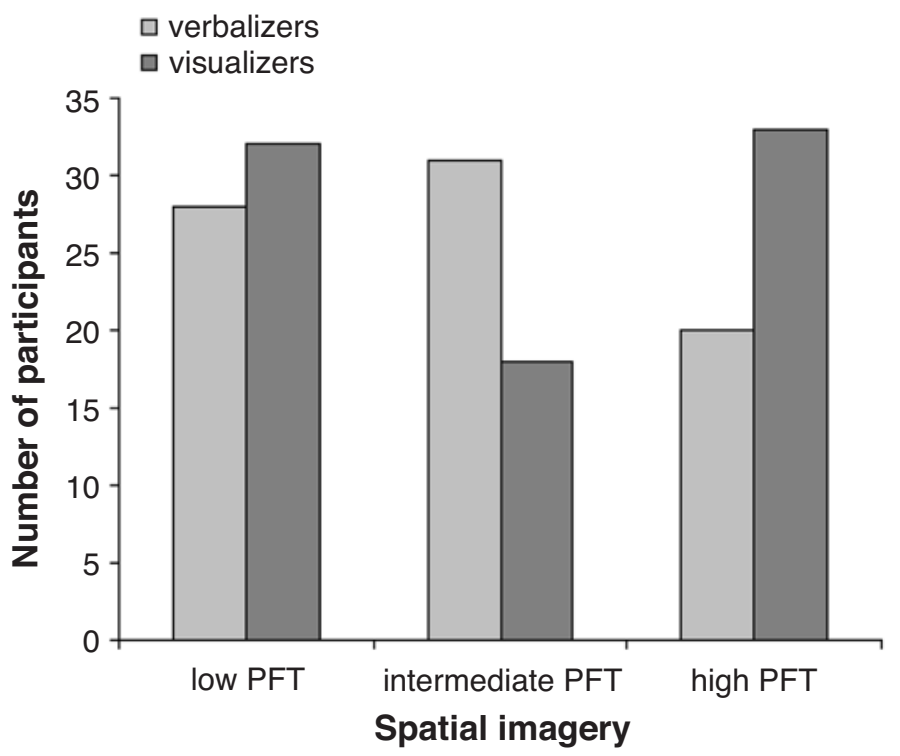

Figure 1. Number of visualizers versus verbalizers who scored low, intermediate, and high on the Paper Folding Test (PFT). 
mediate, and high in spatial imagery, as assessed by the PFT. A chi-square test revealed that the distribution of low, intermediate, and high spatial visualization ability was significantly different for visualizers and verbalizers $\left[\chi^{2}(2)=6.81, p<.05\right]$. As can be seen in Figure 1, the visualizers were not a homogeneous group; there were two distinct subgroups: high spatial and low spatial visualizers, with a significantly smaller number of visualizers of intermediate spatial imagery ability. In contrast to the visualizers, the distribution of the verbalizers' scores did not show such bimodality. These results are consistent with previous findings in Kozhevnikov et al. (2002), which documented two contrasting groups of visualizers: those who had good spatial imagery and those who had poor spatial imagery. ${ }^{3}$

At first glance, the fact that there are low spatial visualizers may seem puzzling. Why do these people prefer to use imagery, instead of analytical methods, to process information when they have poor spatial imagery? We considered two alternatives: (1) Low spatial visualizers have poor imagery abilities but, nevertheless, prefer to use imagery because they also lack verbal-analytical ability, and (2) low spatial visualizers prefer to use men- tal imagery because they are, in fact, good at some forms of imagery - just not the forms required to perform well on spatial visualization tests. In this case, they may excel at object imagery. To investigate these alternatives, we examined how the visualizers and verbalizers scored on the VVIQ. In order to identify the participants who scored especially high or low, we again classified scores as low (scores in the bottom $33.3 \%$ of the distribution), intermediate (scores in the middle $33.3 \%$ ), or high (scores in the top 33.3\%). Figures $2 \mathrm{~A}$ and $2 \mathrm{~B}$ present the number of low spatial, intermediate spatial, and high spatial visualizers and verbalizers, respectively, who scored low, intermediate, and high on the VVIQ. A chisquare test revealed significant differences among low, intermediate, and high spatial visualizers with respect to their VVIQ scores $\left[\chi^{2}(4)=14.81, p<.01\right]$. As can be seen in Figure 2A, for the most part, the visualizers scored high either on the PFT or on the VVIQ. Furthermore, most (62.5\%) low spatial visualizers scored high on the VVIQ. At the same time, most (63.3\%) visualizers who scored high on the VVIQ had low spatial imagery ability. There were only a few visualizers who scored high on both the PFT and the VVIQ (8.4\%) or
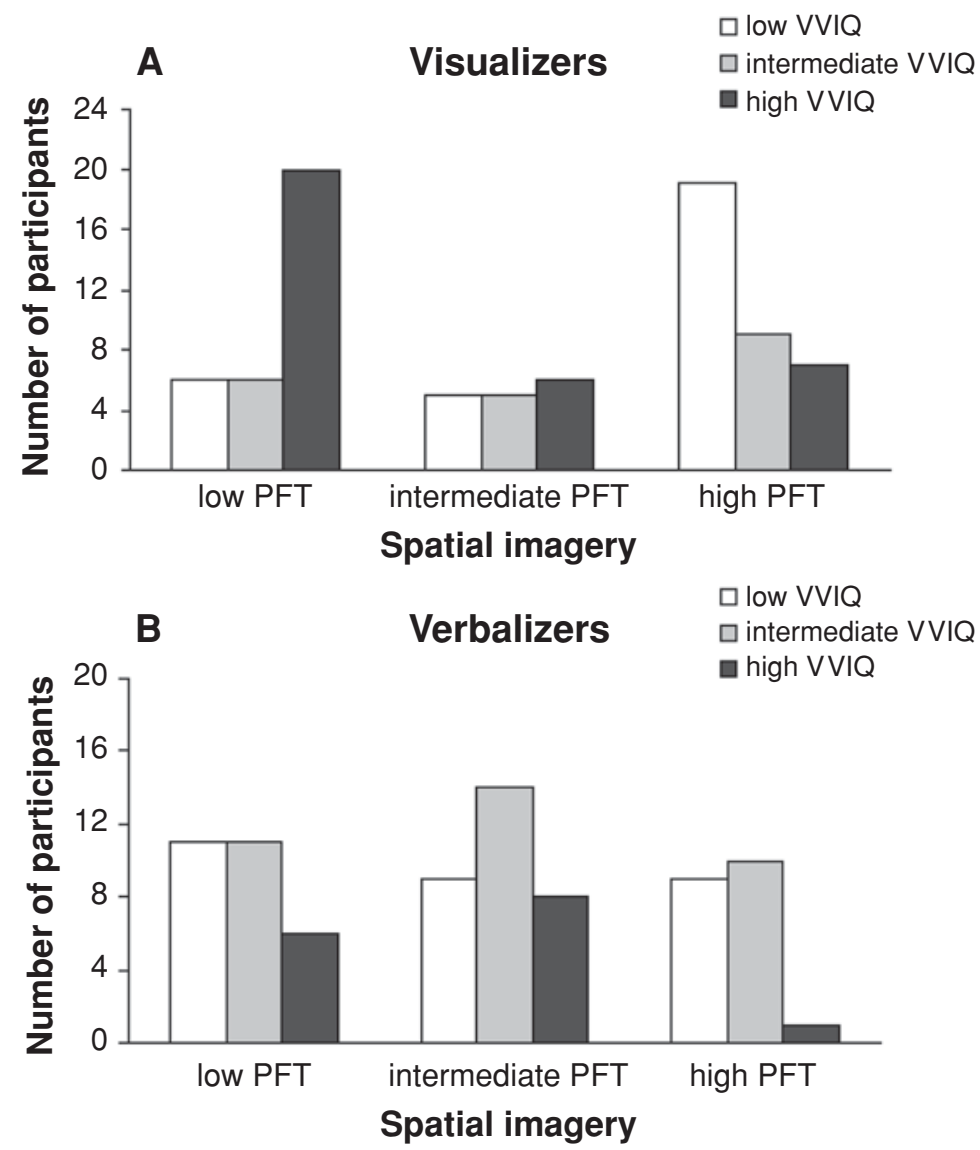

Figure 2. Number of low, intermediate, and high (A) spatial visualizers and (B) verbalizers who scored low, intermediate, and high on the Vividness of $\mathrm{Vi}$ sual Imagery Questionnaire (VVIQ). PFT, Paper Folding Test. 
who scored low on both tests (7.2\%). As for the verbalizers, they generally did not score high on the PFT or on the VVIQ. A chi-square test revealed that the difference among low, intermediate, and high spatial verbalizers with respect to their VVIQ scores was not significant $\left[\chi^{2}(4)=4.14, p=.38\right]$. Further analysis (a one-way analysis of variance [ANOVA] ) confirmed that there was a significant difference in the VVIQ scores for visualizers of differing spatial imagery ability $[F(2,83)=3.92$, $\left.M S_{\mathrm{e}}=92.417, p<.05\right]$. Pairwise comparisons ${ }^{4}$ revealed that visualizers with low spatial imagery reported significantly more vivid mental imagery than did visualizers with high spatial imagery $(p<.05)$. No significant difference was found in the VVIQ scores among verbalizers of low, intermediate, and high spatial imagery $\left[F(2,79)=1.44, M S_{\mathrm{e}}=81.509, p=.24\right]$. The mean VVIQ scores for visualizers and verbalizers of differing spatial imagery ability are shown in Table 2 .

Finally, a chi-square analysis revealed marginal differences between the numbers of females and males in the two groups of visualizers $\left[\chi^{2}(1)=2.37, p=.1\right]$. In the group that scored low on the PFT and high on the VVIQ, $36 \%$ were males and $64 \%$ were females; in the group that scored high on the PFT and low on the VVIQ, $57 \%$ were males and $43 \%$ were females.

In summary, as was predicted, we found a bimodal distribution of visualizers' scores on the PFT and the VVIQ, whereas the verbalizers' scores were not distributed in this way. These findings suggest that visualizers, in contrast to verbalizers, are not a homogeneous group but rather consist of two different types: spatial visualizers and object visualizers. Although the gender differences were not significant, the trend might suggest that females tend to be object visualizers and males tend to be spatial visualizers. However, the results show that the difference between spatial and object visualizers cannot be reduced to a gender difference; numerous men were object visualizers, and numerous women were spatial visualizers.

Furthermore, the fact that most high spatial visualizers scored low on the VVIQ whereas most low spatial visualizers scored high provides evidence that the ability to generate vivid, high-resolution visual images and the ability to perform spatial transformations rely on distinct processes. These results help to explain the apparent lack of correlation between scores on the traditional visualizerverbalizer cognitive style dimension and those on visualspatial tasks: The relationship between the use of imagery strategies and imagery ability cannot be characterized as variation along a single dimension. Failure to appreciate this fact led previous researchers to the misleading conclusion that "verbalizers outperform more visual students on spatial tests" (Lean \& Clements, 1981, p. 296) or that "it is tenuous to equate a vivid imager with a visualizer ... since in all probability, the two are separate issues" (Strosahl \& Ascough, 1981, p. 429). Thus, instead of a dichotomous cognitive style dimension (visualizers vs. verbalizers), the results of Study 1 suggest the existence of three dimensions: verbalizers, object visualizers, and spatial visualizers.

A limitation of Study 1, however, is that the object imagery survey (the VVIQ) was a self-report measure and, therefore, subjective. Study 2 was designed to examine whether object visualizers are, in fact, better than spatial visualizers on objective measures of object imagery.

\section{STUDY 2}

To measure object imagery, we designed two computerized tasks. The first, the grain resolution task, was designed to assess participants' ability to generate detailed, high-resolution images of individual objects. In this task, the participants read the names of pairs of objects and used imagery to evaluate which object in each pair had the surface with the finer texture or denser grain. The second task, the degraded pictures task, was designed to assess participants' ability to recognize and identify an object presented in a degraded picture. In this task, we assumed that top-down processing would be used to complete obscured portions of the object and that this completion process would rely on the same mechanisms that underlie object imagery (see Kosslyn, 1994).

In addition, we administered a version of the Shepard and Metzler (1971) mental rotation task to assess spatial imagery, and we designed a computerized embedded pictures task to tap either spatial or object aspects of imagery, depending on the type of question asked about the stimuli. In half of the items of the embedded pictures task, the participants were to identify global properties that characterized the entire picture, such as symmetry, whereas in the other half of the items, the participants were to identify local properties that characterized only a part of the picture, such as a particular type of junction connecting two lines in the image. Kosslyn and Anderson (summarized in Kosslyn, 1994, chap. 9) provided evidence that object imagery is formed on the basis of individual perceptual units stored in visual memory, whereas spa-

Table 2

Mean Scores and Standard Deviations on the Vividness of Visual Imagery Questionnaire (out of 80) as a Function of Cognitive Style and Spatial Ability

\begin{tabular}{|c|c|c|c|c|c|c|}
\hline & \multicolumn{2}{|c|}{ Low Spatial } & \multicolumn{2}{|c|}{ Intermediate Spatial } & \multicolumn{2}{|c|}{ High Spatial } \\
\hline & $M$ & $S D$ & $M$ & $S D$ & $M$ & $S D$ \\
\hline Visualizers & 67.98 & 9.60 & 63.73 & 9.05 & 60.14 & 9.83 \\
\hline Verbalizers & 62.40 & 9.87 & 61.55 & 8.67 & 58.12 & 8.17 \\
\hline
\end{tabular}


tial images are necessarily formed by using spatial representations to arrange components sequentially. Because global properties characterize an entire picture, we predicted that the participants would rely on object imagery to identify these properties in embedded pictures; by the same token, because local properties characterize only part of an image, we predicted that in order to assess such properties, the participants would generate the image part by part and, therefore, would rely on spatial imagery.

\section{Method}

Participants. All the participants who took part in Study 1 were invited to participate in Study 2. Overall, 51 participants (28 females and 23 males) who previously had taken part in Study 1 volunteered to take part in this study. On the basis of their scores from Study 1 , the participants were divided into verbalizers $(n=26)$, object visualizers $(n=12)$, and spatial visualizers $(n=13)$.

Materials and Procedure. All the participants were tested individually. They sat $35-45 \mathrm{~cm}$ in front of a computer screen and saw stimuli presented by a Macintosh PowerMac G3, on an NEC E700 monitor with a resolution of $1,024 \times 768(75 \mathrm{~Hz})$. The participants received four computerized tasks: Shepard and Metzler (1971) mental rotation, grain resolution, degraded pictures, and embedded pictures. All the tasks were presented with the PsyScope program (Cohen, MacWhinney, Flatt, \& Provost, 1993). The order of the tasks was counterbalanced. There was no set time limit on the tasks, but the participants were instructed to respond as quickly and accurately as possible; speed and accuracy were measured in all the tasks.

Shepard and Metzler mental rotation task. In this computerized version of the Shepard and Metzler (1971) mental rotation task, the participants saw pairs of two-dimensional pictures of angular threedimensional forms. The forms in a pair were rotated from $0^{\circ}$ to $180^{\circ}$ relative to each other, within the picture plane. Half the pairs contained identical shapes, and half contained mirror images. The participants were asked to judge whether the forms in a pair had the same shape or were mirror images. There were 9 practice trials and 109 test trials. The internal reliability of the task for accuracy was .88 .

Degraded pictures task. The degraded pictures task was adapted from the Snow Pictures Test of Ekstrom et al. (1976). In each trial of this task, the participants saw a degraded line drawing of a common object (e.g., an umbrella, a pair of scissors, or a table). In some cases in which it was judged that the line drawings were too easy to distinguish from the background noise, further degradation was introduced using Adobe Photoshop. Once the participants had identified the object in the picture, they were to press the Return key. After doing this, the picture disappeared, and the participants had to type the name of the object, after which the next degraded picture appeared on the screen. There were 2 practice trials and 10 test trials. The internal reliability of the task for accuracy was .73. An example from the degraded pictures task is shown in Figure 3A. Figure 3B shows the outline of the degraded object hidden in Figure 3A.

Grain resolution task. On each trial of this task, the participants saw a pair of names of objects written on the computer screen and identified which of the two named objects had a finer texture, or denser grain. Grain referred to bits or particles per unit of area or volume. Some examples of grain include the density of spots per area (leopard skin vs. giraffe skin), number of particles per unit of volume (a heap of grains of salt vs. a heap of poppy seeds), and number of air bubbles per volume (soda vs. shampoo). The pairs of words were presented on the computer screen, one pair at a time, and the two words were separated by a dash. If the participant believed that the object named on the left side of the dash had a denser grain, he or she was to press the "b" key on the keyboard, whereas
A

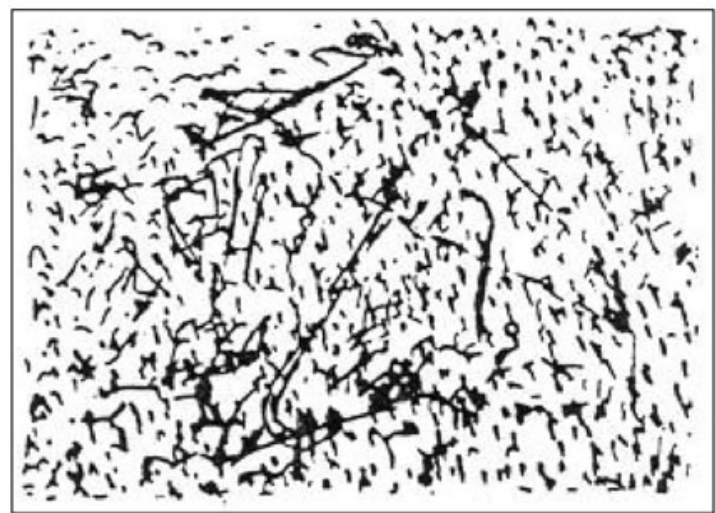

B

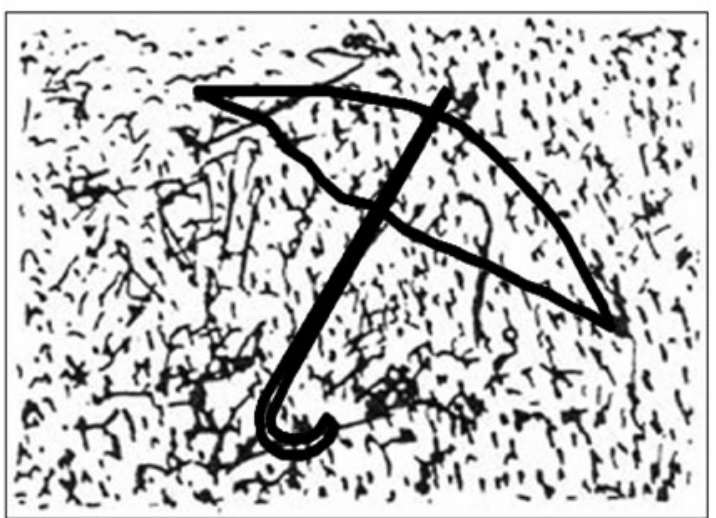

Figure 3. (A) Example item (umbrella) from the degraded pictures task. (B) The outline of the umbrella hidden in the picture.

if he or she believed that the object named on the right had the denser grain, he or she was to press the "n" key. After the participant had responded, the pair disappeared, and a new pair appeared on the screen. The task consisted of 2 practice and 20 test trials. The internal reliability of the task for accuracy (alpha-Cronbach) was .62.

Computerized embedded pictures task. This task was adapted from that of Rouw, Kosslyn, and Hamel (1997). The participants viewed line drawings of common objects (e.g., a piano, a sailboat, or a stool). They had to decide whether specific global or local properties were present. The global properties were symmetry (along any axis) and parallelism (i.e., two or more lines in the drawing were parallel); the local properties were an arrow junction (three line segments that meet to form an arrow) and a T-junction (two perpendicular lines that intersect at a point to form a T). Figure 4 provides examples of the stimuli. The drawings were from Snodgrass and Vanderwart (1980). We recorded four auditory cues (the words symmetry, parallelism, arrow junction, and T-junction) with Macromedia SoundEdit 16; each recording was approximately $1 \mathrm{sec}$ in duration. During the trials, a fixation asterisk was presented for $0.75 \mathrm{sec}$, and then the picture was displayed on the screen for $2.5 \mathrm{sec}$. The picture then disappeared, and the participants visualized it on the blank white screen. The screen remained blank for $2 \mathrm{sec}$, and then one of the four property cues was presented auditorily. The participants decided whether or not the picture contained the named property. The 16 test trials were divided so that there were 4 trials for each of the four properties. The internal reliability of the task for accuracy on global properties items (alpha-Cronbach) was .56 and on local properties items was .54 . 
A

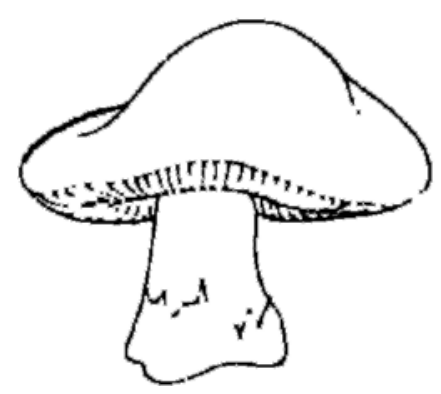

B

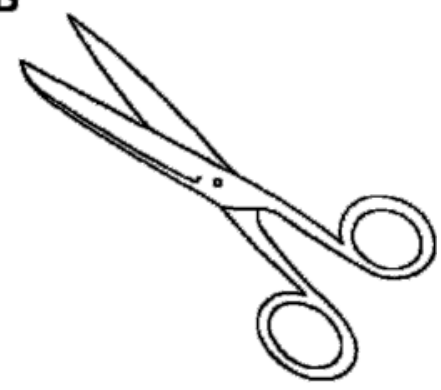

Figure 4. Example of the picture stimuli presented to participants in the embedded pictures task. (A) Participants were asked to decide whether the picture was symmetrical (global property; the answer is "no"). (B) Participants were to decide whether a $\mathrm{T}$-junction was present in the picture (local property; the answer is "yes").

\section{Results and Discussion}

We assessed overall accuracy and response latency from the mental rotation, grain resolution, and degraded pictures tasks. The mean proportions correct and response times for each task are presented in Figures 5 and 6 , respectively, as a function of cognitive style. The data were analyzed in a $3 \times 3$ repeated measures ANOVA, with task as a within-subjects variable and cognitive style (object visualizers, spatial visualizers, and verbalizers) as a between-subjects variable. The accuracy and response time data were considered in separate analyses. For accuracy, there was a main effect of task $[F(2,96)=$ $\left.161, M S_{\mathrm{e}}=1.437 \mathrm{E}-02, p<.0001\right]$, indicating that the participants were not equally accurate on all tasks. The main effect of cognitive style was not reliable $[F(2,50)=$ $\left.1.62, M S_{\mathrm{e}}=4.154 \mathrm{E}-03, p=.2\right]$. However, there was a reliable interaction between task and cognitive style $\left[F(4,96)=5.39, M S_{\mathrm{e}}=1.437 \mathrm{E}-02, p<.001\right]$, which indicates that object visualizers, spatial visualizers, and verbalizers performed differently on different imagery tasks. Pairwise comparisons revealed that object visualizers were less accurate than either spatial visualizers or verbalizers $(p<.01)$ on the mental rotation task, whereas no difference was found between verbalizers and spatial visualizers $(p=.7)$. At the same time, object visualizers were more accurate than spatial visualizers $(p<.05)$ on the grain resolution task, whereas there was no difference between verbalizers and object visualizers $(p=$ .9). For the degraded pictures task, object visualizers performed better than verbalizers $(p<.05)$ and marginally better than spatial visualizers $(p=.06)$, but there was no difference in how accurately the verbalizers and spatial visualizers performed this task $(p=.9)$.

For response times, there also was a main effect of task $\left[F(2,96)=44.74, M S_{\mathrm{e}}=1.3 \mathrm{E}+07, p<.001\right]$, indicating that the participants required more time for some tasks than for others. The main effect of cognitive style was not reliable $\left[F(2,96)=1.62, M S_{\mathrm{e}}=1.4 \mathrm{E}+07\right.$,

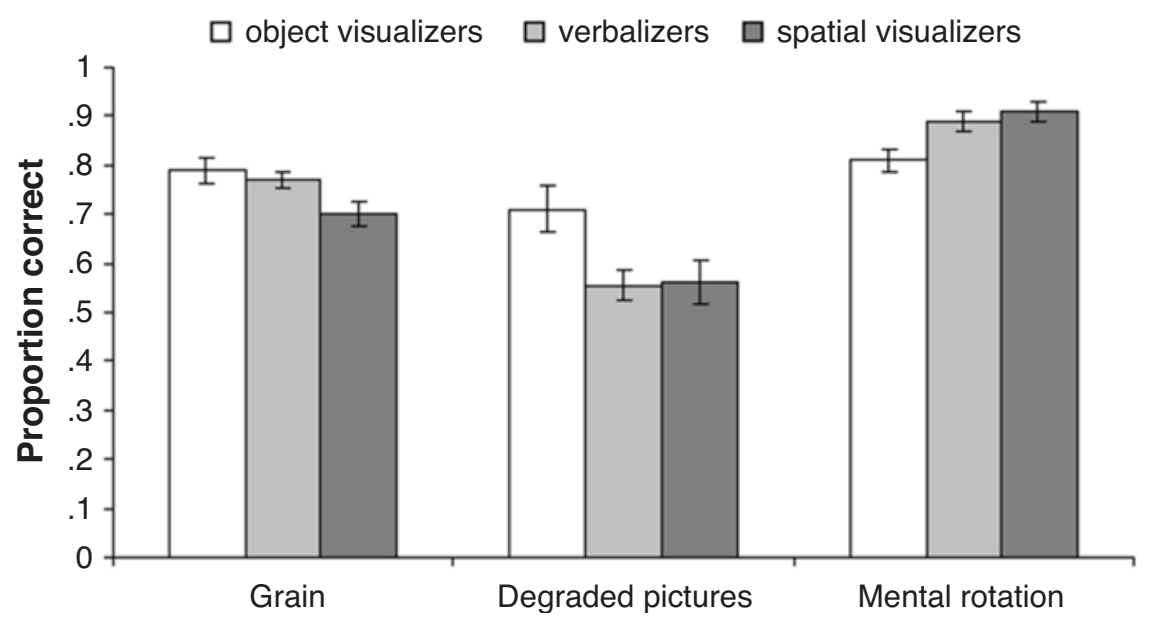

Figure 5. Mean proportions correct for the grain resolution, degraded pictures, and Shepard and Metzler mental rotation tasks as a function of cognitive style. 


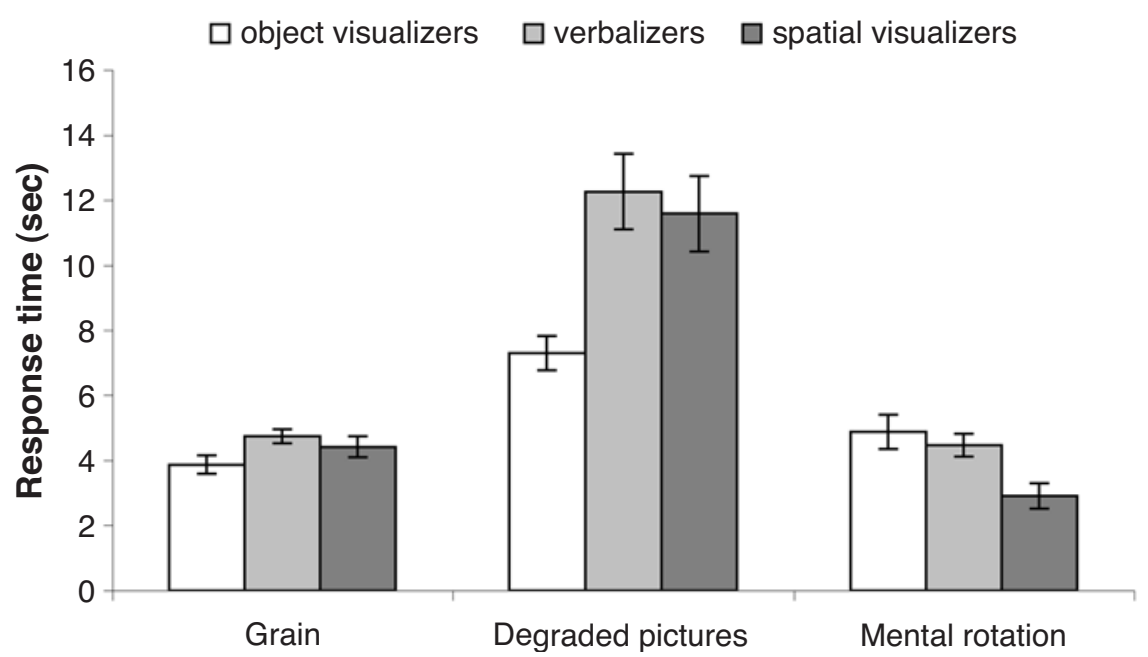

Figure 6. Mean response times of object visualizers, verbalizers, and spatial visualizers on the grain resolution, degraded pictures, and Shepard and Metzler mental rotation tasks.

$p=.2]$. However, there was a reliable interaction between task and cognitive style $\left[F(4,96)=3.07, M S_{\mathrm{e}}=\right.$ $1.3 \mathrm{E}+07, p<.05]$. The spatial visualizers were faster than both the object visualizers and the verbalizers $(p<$ .05 ) on the mental rotation task, whereas the object visualizers and the verbalizers required comparable amounts of time $(p=.8)$. The finding that verbalizers were as accurate as spatial visualizers on the mental rotation task, whereas their response times were significantly longer, suggests that verbalizers might use nonspatial strategies to solve the mental rotation problems.

There were no significant differences in response times among the three groups of participants in the grain resolution task $(p>.7)$. That there was no difference between verbalizers and object visualizers in either speed or accuracy on the grain resolution task may imply that the task could be performed on the basis of verbally coded knowledge about the density or grain of the two objects. In fact, Blajenkova and Kozhevnikov (2002) showed that performance on many of the grain resolution items correlates highly with scores on verbal analogy tests. On the degraded pictures task, the performance of object visualizers was faster than that of verbalizers $(p<.05)$ and marginally faster than that of spatial visualizers $(p=.08)$. We did not find a significant difference between the response times of spatial visualizers and verbalizers $(p=.9)$.

In addition, we assessed accuracy and latency for two property types (global and local) in the embedded pictures task. The mean scores for each property type are shown in Figure 7 as a function of cognitive style. The latency data are shown in Table 3 . We conducted a $2 \times 3$ ANOVA for the embedded pictures task, using property type (global vs. local) as a within-subjects variable and cognitive style (object visualizers, spatial visualizers,

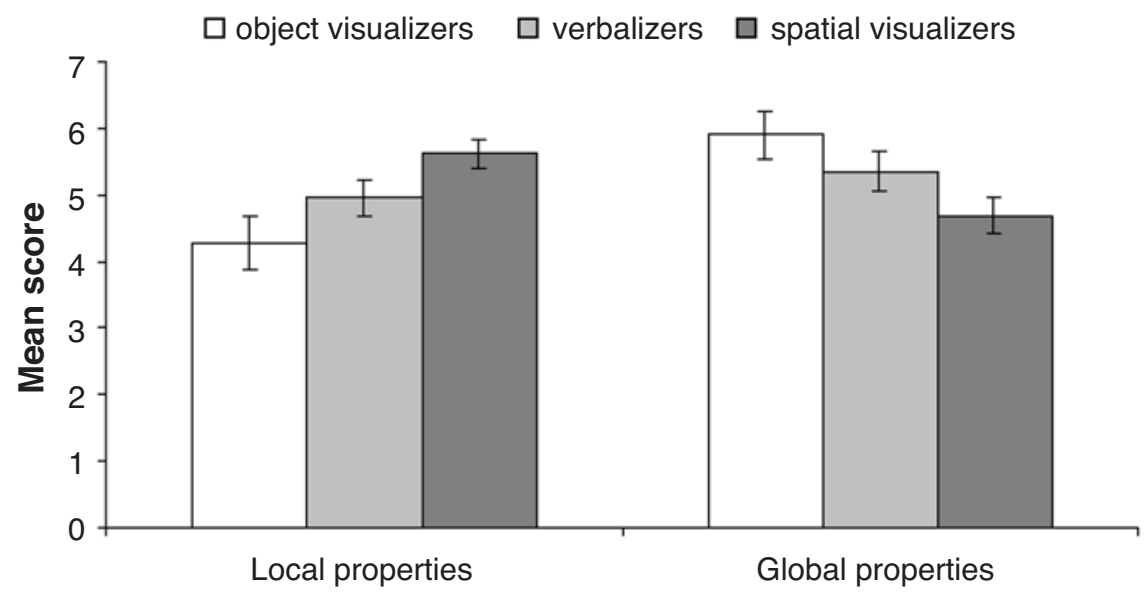

Figure 7. Mean scores on the items of the embedded pictures task that required the identification of local and global properties as a function of cognitive style. 
Table 3

Latency Data (Means and Standard Deviations, in Milliseconds) for the Embedded Pictures Task (Global and Local Properties) as a Function of Cognitive Style

\begin{tabular}{|c|c|c|c|c|c|c|}
\hline \multirow[b]{2}{*}{ Task Property } & \multicolumn{2}{|c|}{ Verbalizers } & \multicolumn{2}{|c|}{ Object Visualizers } & \multicolumn{2}{|c|}{ Spatial Visualizers } \\
\hline & $M$ & $S D$ & $M$ & $S D$ & $M$ & $S D$ \\
\hline Global & 2,541 & 1,109 & 2,704 & 927 & 2,919 & 1,161 \\
\hline Local & 3,251 & 1,198 & 3,496 & 1,336 & 3,187 & 933 \\
\hline
\end{tabular}

and verbalizers) as a between-subjects variable, first for accuracy and then for response times. For accuracy, there was no difference between the two types of properties $\left[F(1,49)=1.92, M S_{\mathrm{e}}=2.022, p=.17\right]$ and no main effect of cognitive style $[F(1,49)<1]$. However, we did find that the two variables interacted $[F(2,49)=6.92$, $\left.M S_{\mathrm{e}}=2.022, p<.05\right]$, which shows that the groups differed in how accurately they identified global versus local properties. Pairwise comparisons revealed that object visualizers were more accurate than spatial visualizers when they identified global properties $(p<.05)$, whereas spatial visualizers were more accurate than object visualizers when they identified local properties $(p<.01)$. For both types of property judgments, verbalizers scored in between the object visualizers and the spatial visualizers (see Figure 7). For response time, there was no effect of property type or cognitive style, nor was the interaction between property type and cognitive style significant.

In short, the results from Study 2 nicely dovetail with those from Study 1. Object visualizers are, indeed, clearly different from spatial visualizers. Object visualizers were more accurate and faster on the degraded pictures task, which requires recognizing individual shapes. In addition, they were more accurate than spatial visualizers on the grain resolution task, which requires generating detailed, high-resolution images. In contrast, spatial visualizers were more accurate and faster than object visualizers in the mental rotation task, which requires rotating images of three-dimensional figures. On the basis of these results, one could argue that spatial visualizers are more accurate and faster in generating and manipulating dynamic images, whereas object visualizers are more accurate and faster in generating static images. However, the differences between object and spatial visualizers cannot be reduced to differences in their performance of dynamic versus static tasks. The results from the embedded pictures task showed that object visualiz- ers were also more holistic and performed better on the trials that required identifying global properties of shapes, whereas spatial visualizers were more successful in identifying local properties.

\section{STUDY 3}

One possible explanation for the results of Study 2 is that object visualizers, in contrast to spatial visualizers, have difficulty processing abstract information, and thus they perform worse on spatial imagery tasks that require manipulation of abstract mental images. The goal of Study 3 was to compare the general and verbal intelligence of object visualizers, spatial visualizers, and verbalizers and to examine how the three groups process abstract information.

\section{Method}

Participants. All the participants who had participated in Study 2 were invited to participate in Study 3. Overall, 42 participants (23 males and 19 females) who had participated in Study 2 volunteered to take part in this study. On the basis of their scores from Study 1 , the participants were divided into verbalizers $(n=21)$, object visualizers $(n=11)$, and spatial visualizers $(n=10)$.

Procedure. The participants were given two tests: the Advanced Progressive Matrices (APM; Raven, Raven, \& Court, 1998), which is a widely used nonverbal measure of fluid reasoning, and the Wechsler Abbreviated Scale of Intelligence: Similarities (WASI; Wechsler, 1999), which is considered to be a measure of verbal intelligence. The APM consisted of a complete set of 36 items, each of which contained a pattern or design. A portion of the pattern was missing, and the task was to find which of eight possible answers best completed the pattern or design. In the WASI, the participants were presented with a complete set of 19 pairs of words and had to describe how two named qualities, characteristics, or states were alike (e.g., red and blue, love and hate, freedom and law). The score for each item depended on the degree to which the response described a general property primarily pertinent to both words in the pair.

The participants first completed the APM and then the WASI. For the APM, the participants were allotted $30 \mathrm{~min}$; there was no time limit for the WASI.

Table 4

Mean Scores and Standard Deviations for the Wechsler Abbreviated Scale of Intelligence (WASI) and the Advanced Progressive Matrices (APM) Tests as a Function of Cognitive Style

\begin{tabular}{|c|c|c|c|c|c|c|}
\hline \multirow[b]{2}{*}{ Test } & \multicolumn{2}{|c|}{ Verbalizers } & \multicolumn{2}{|c|}{ Object Visualizers } & \multicolumn{2}{|c|}{ Spatial Visualizers } \\
\hline & $M$ & $S D$ & $M$ & $S D$ & $M$ & $S D$ \\
\hline WASI & 38.52 & 3.60 & 37.27 & 3.07 & 36.80 & 6.73 \\
\hline APM figural & 14.38 & 5.30 & 15.40 & 3.92 & 16.08 & 4.37 \\
\hline APM analytical & 8.19 & 3.74 & 3.20 & 1.03 & 10.27 & 2.61 \\
\hline
\end{tabular}


A

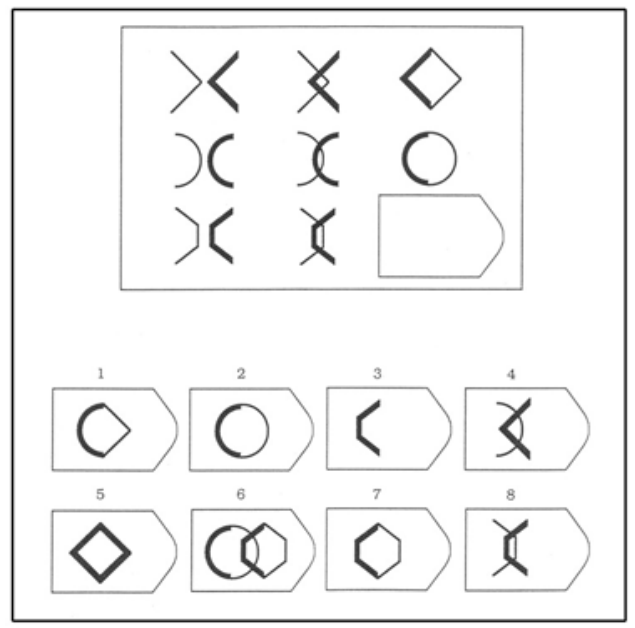

B

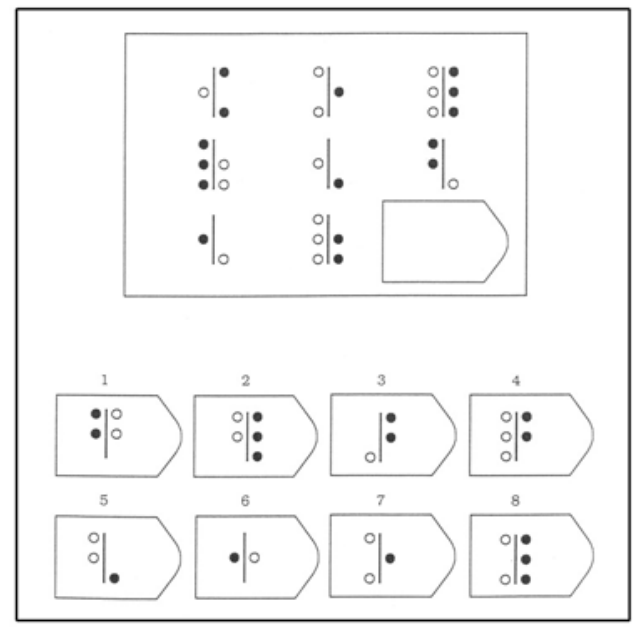

Figure 8. Examples of Advanced Progressive Matrices problem types: (A) a figural problem and (B) an analytical problem. The participants were instructed to use the eight patterns in the upper array to determine which of the eight alternative responses should appear in the bottom right position.

\section{Results and Discussion}

The mean scores for verbalizers, object visualizers, and spatial visualizers on the WASI and the APM are presented in Table 4. There was no difference among the three groups on the WASI. However, a one-way ANOVA revealed a difference among the groups on the APM $\left[F(2,41)=4.53, M S_{\mathrm{e}}=27.174, p<.05\right]$. Pairwise comparisons indicated that the spatial visualizers performed significantly better on this test than did the object visualizers $(p<.05)$.

To examine further the performance of the object versus the spatial visualizers on the APM, we distinguished between two different classes of matrices problems: figural and analytical. This distinction has previously been offered by several researchers (Carpenter, Just, \& Shell,
1990; Hunt, 1975; Prabhakaran, Smith, Desmond, Glover, \& Gabrieli, 1997). Figural problems require primarily visual-spatial analysis and are based on perceptual operations or characteristics, such as continuation or superimposition. Note that these characteristics can be processed using either spatial or object imagery. Analytical problems, in contrast, are thought to require abstract-analytical reasoning. Examples of figural and analytical problems are provided in Figure 8. We identified 19 figural and 17 analytical problems in the APM. Although the groups performed comparably on the figural problems $[F(2,41)=$ $\left.2.45, M S_{\mathrm{e}}=34.145, p=.10\right]$, they differed markedly on the analytical problems $\left[F(2,41)=15.17, M S_{\mathrm{e}}=18.877\right.$, $p<.001]$. Object visualizers were worse $(p<.001)$ than both spatial visualizers and verbalizers on this type of problem.

In summary, object visualizers were comparable to the other groups in abstract verbal reasoning and in using visual analysis to solve the figural items in the APM. In contrast, object visualizers performed significantly worse than spatial visualizers and verbalizers on the analytical problems in the APM. A closer look at these items suggests an account for this finding: The analytical problems in the $\mathrm{APM}$, in fact, appear to require spatial reasoning. Indeed, when Prabhakaran et al. (1997) examined brain activation while participants solved figural and analytical problems, they found that analytical problems activated posterior parieto-occipital areas associated with spatial processing. Because object visualizers tend to process visual images globally, their poor performance on the analytical problems might reflect difficulty in forming categorical spatial relations, rather than a lack of general abstract thinking. These results are consistent with those of Kozhevnikov et al. (2002), who reported that object visualizers had difficulty interpreting abstract graph problems; they consistently considered only the global shape of the graph and did not attempt to restructure the graph visually and consider each interval successively.

\section{STUDY 4}

Although relying on object imagery may impair performance on tasks that require one to consider spatial relations or mentally transform the orientation or location of patterns, such imagery should be useful for many other types of tasks. For example, we have provided evidence that object imagery can help one to recognize degraded pictures (where one can use imagery to complete a shape) and to generate high-resolution, detailed images of shape. In addition, object visualizers, who are especially good in generating vivid pictorial images, may excel in such tasks as drawing or painting, whereas spatial visualizers may succeed in such tasks as science and engineering. Study 4 was designed as a preliminary investigation to compare how members of different professions - namely, visual artists versus scientists - perform on object and spatial imagery tests. 


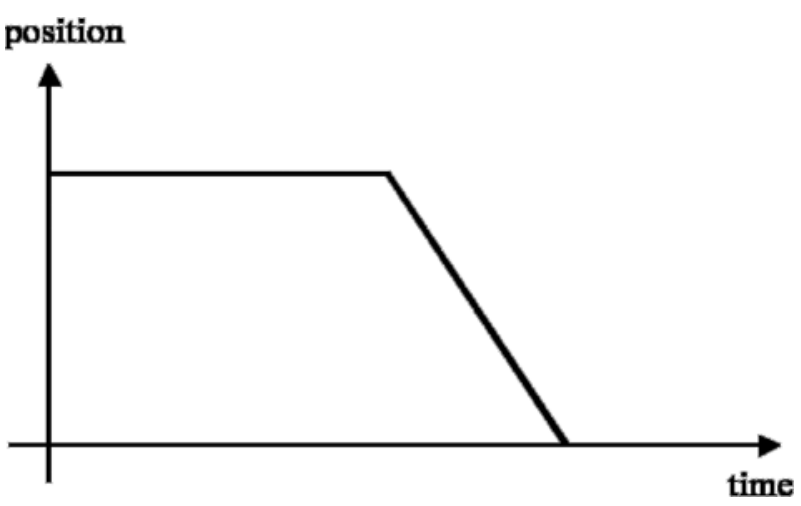

Figure 9. Example graph problem presented to the scientists and visual artists.

\begin{abstract}
Method
Participants. The participants were 10 visual artists and 14 scientists. The group of scientists included physicists $(n=10)$ and engineers $(n=4)$ with at least a graduate degree in the field and several years of research or professional experience. The group of visual artists included professional painters $(n=6)$, photographers $(n=2)$, and interior designers $(n=2)$ with at least 2 years of professional experience in the field. All the participants were selected on the basis of pilot interviews in which they reported their preferences for using imagery versus verbal-analytical strategies in their work and in everyday life.

Procedure. The participants were asked to complete the pretest questionnaire. They were then given the same version of the PFT as that used in Study 1 and a paper-and-pencil version of the grain resolution task. The paper-and-pencil version of the grain resolution task included the same 20 pairs of items that we used in the computerized version in Study 2. The participants were given only $3 \mathrm{~min}$ to take the PFT and 5 min to complete the grain resolution task.

In addition, the participants were shown a graph that depicted an object's position as a function of time (see Figure 9) and were asked to visualize, describe, and draw the situation represented by the graph. The correct description of the graph is that the object initially is stationary (its position remains the same in the first interval of the graph), then moves at a constant velocity in the second interval (its position changes linearly with time), and finally comes to a stop (its position remains constant again).
\end{abstract}

\section{Results and Discussion}

The mean scores on the paper folding and grain resolution tasks are shown in Table 5 as a function of profession. We performed a two-way ANOVA with task (paper folding and grain resolution) as a within-subjects variable and profession (scientists vs. artists) as a betweensubjects variable. The results revealed neither an effect of task nor an effect of profession. However two variables did interact $\left[F(1,22)=6.29, M S_{\mathrm{e}}=5.670, p<.05\right]$. Pairwise comparisons showed that the scientists performed better than the visual artists on the PFT $(p=.02)$, whereas the visual artists performed better than the scientists on the grain resolution task ( $p=.03)$.

In addition, we coded all the participants' responses on the graph problem into three categories: (1) a pictorial interpretation, in which the participant interpreted the graph literally as a pictorial illustration of a situation; (2) an irrelevant interpretation, in which the participant interpreted the graph (correctly or incorrectly) by visualizing irrelevant, but not pictorial, features of the graph; or (3) a schematic interpretation, in which the participant referred to the graph as an abstract schematic representation (independently of whether the actual interpretation was correct or incorrect). Two independent raters analyzed the participants' responses to the graph question, and the interrater reliability was .93. Consistent with previous findings that object visualizers tend to interpret graphs as literal pictures of the situation (Kozhevnikov et al., 2002), 8 (out of 10) visual artists interpreted the graph problem as a literal pictorial illustration of a situation or as the path of the actual motion and did not attempt to interpret the graph as an abstract schematic representation. The artists consistently referred to the global shape of the graph and expected the shape of the graph to resemble the path of the actual motion. An example of an artist's report is illustrated in Figure 10. In contrast, all 14 scientists produced schematic descriptions of the situation depicted in the graph; an example of a typical scientist's response is also given in Figure 10. The difference between visual artists' and scientists' interpretations of the graph was highly significant $\left[\chi^{2}(2)=20.16\right.$, $p<.0001]$.

The scientists and the artists clearly had different sorts of imagery. Different professions might promote object versus spatial imagery, or perhaps people with one sort of imagery select a field on the basis of their imagery abilities or preferences. The fact that the scientists were much more successful when interpreting graphs is not surprising, given their experience with graphs during their professional work. What was surprising, however, is the clear qualitative difference in the scientists' and the visual artists' drawings and descriptions. One might argue, however, that the graph presented to the participant is abstract and its interpretation requires prior experience with graphs. However, it is interesting to note that previous findings reported by Kozhevnikov et al. (2002) showed the same qualitative difference in graph interpretation between object and spatial visualizers who had the same mathematical background but who did not take any science or physics classes at high school or college levels (and thus, neither group was exposed, at least in courses, to scientific graphs). These diverse responses suggest that the two types of people do, in fact, visualize the world in different ways.

Table 5

Mean Scores and Standard Deviations for the Paper Folding and Grain Resolution Tasks as a Function of Profession

\begin{tabular}{lrrrrr}
\hline \multirow{2}{*}{ Task } & \multicolumn{2}{c}{ Visual Artists } & & \multicolumn{2}{c}{ Scientists } \\
\cline { 2 - 3 } \cline { 6 - 7 } \multicolumn{1}{c}{} & $M$ & $S D$ & & $M$ & $S D$ \\
\hline Paper folding & 5.15 & 2.76 & & 7.14 & 1.01 \\
Grain resolution & 12.51 & 1.58 & & 11.27 & 2.55 \\
\hline
\end{tabular}


Visual artist's response:

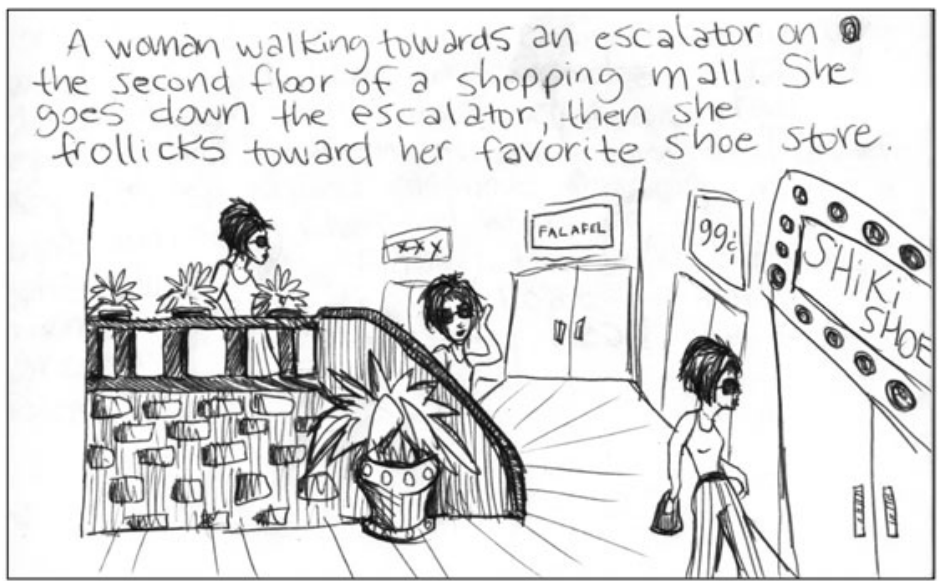

Scientist's response:

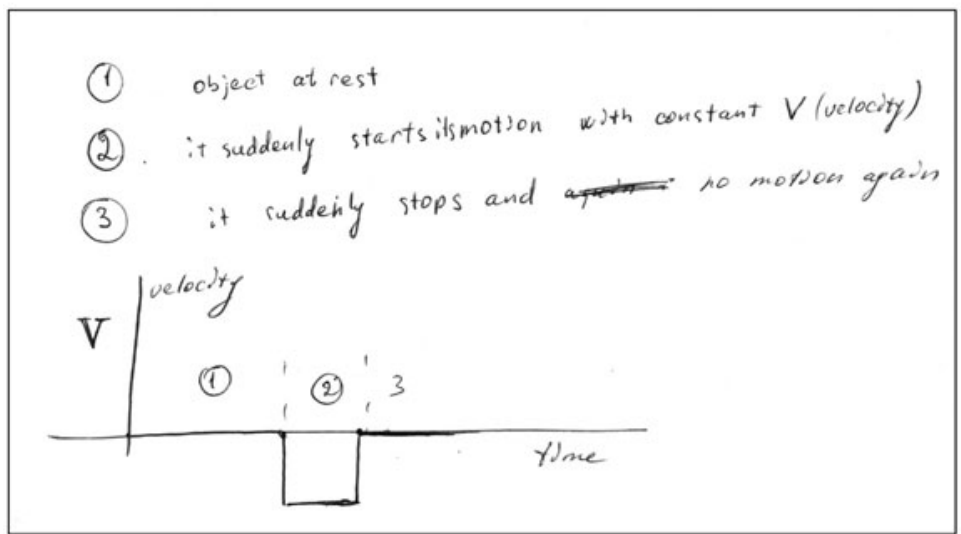

Figure 10. Example of a visual artist's response (top) and a scientist's response (bottom) to the graph problem.

\section{GENERAL DISCUSSION}

The findings in these four studies support an interpretation that there are two qualitatively different types of visualizers. Object visualizers use imagery to construct high-quality images of the shapes of individual objects, whereas spatial visualizers use imagery to represent and transform spatial relations. Furthermore, the results of Studies 1 and 2 show that people who score high on spatial imagery tasks tend to score below average on object imagery tasks, and vice versa for people who score high on object imagery tasks. No such dissociation was found among verbalizers: Verbalizers did not show a clearly marked preference for any particular type of imagery. Therefore, the visualizer-verbalizer cognitive style dimension should be revised to include two types of visualizers - those whose imagery is based primarily on characteristics of objects and those whose imagery is primarily spatial - in addition to verbalizers.
The finding that the two types of visualization are typically mutually exclusive is a puzzle. Logically, they could have been simply two separate dimensions, and a given person's score on one need not be correlated with his or her score on the other. But the results presented in Figure 2 show that there are, in fact, two groups of visualizers: those who excel in spatial imagery, and not object imagery, and those with the opposite proclivities. It is possible that a compensatory mechanism is at work: If one is effective at spatial imagery, one may tend to use this skill more frequently than (or sometimes in lieu of) object imagery in daily life, and vice versa, and thus, one sort of imagery will be practiced and used, whereas another sort will not. Many tasks can be solved using either sort of imagery; for example, planning a route can be accomplished using dead reckoning (relying on spatial imagery) or by recalling a sequence of landmarks (relying on object imagery). However, our results have shown that not all tasks can be solved equally effectively using either sort of imagery. 
Previous research (Paivio \& Clark, 1991; Paivio \& Harshman, 1983; J. T. E. Richardson, 1999) on the visualizer-verbalizer cognitive style dimension suggested that male visualizers use abstract imagery to visualize moving objects, whereas female visualizers use vivid imagery to generate static images. Taking this distinction further, J. T. E. Richardson proposed that females are more efficient in the generation and maintenance of static visual information, whereas males are more efficient in the dynamic manipulation and transformation of such information. However, the results of Studies 1 and 2 show that the distinction between spatial and object visualizers cannot be reduced to gender differences or to differences in processing static versus dynamic visual information.

Rather, our results suggest that object and spatial visualizers encode and process mental images in different ways. Object visualizers tend to encode images globally as a single perceptual unit, which they process holistically. In contrast, spatial visualizers tend to encode and process images analytically, part by part, using spatial relations to arrange and analyze the components. Because they allow the part structure of objects to be made explicit, spatial images may be more flexible and transformable, which might explain why spatial visualizers excel in dynamic image transformations. In contrast, object images encoded as a single unit are not as easily transformed. However, the time needed to generate and activate such an image should not depend on image complexity, and this could explain why object visualizers tend to be faster and more accurate in recognition and memory tasks.

One might be tempted to characterize the difference between object and spatial types of visualizers in terms of the operation of the central executive used in working memory (Baddeley, 1992). The central executive is the component of working memory that controls attention and coordinates the activities of verbal and visual-spatial short-term stores; the central executive also allocates resources for solving a given problem or suppresses information that is irrelevant to the current task (Engle, Kane, \& Tuholski, 1999; O’Reilly, Braver, \& Cohen, 1999). From this perspective, the central executive of object visualizers might have difficulty suppressing details that are not relevant for a given task, which would hamper the ability to abstract the key characteristics of a stimulus. However, the results of Study 3 show that object visualizers perform well on abstract nonvisual tasks, such as a verbal similarities task. Other studies (Kozhevnikov et al., 2002) have also reported that object visualizers score as well as spatial visualizers and verbalizers on the quantitative part of the Scholastic Aptitude Test; moreover, object visualizers are able to successfully use abstract mathematical strategies to solve science problems. Such findings suggest that the difficulties object visualizers have in dealing with abstract spatial relations do not arise because the central executive is not able to suppress irrelevant information but, rather, because of their tendency to process visual information globally.
Could the distinction between object and spatial imagery simply reflect a difference between concrete and abstract representations? Although we cannot rule out this possibility with confidence, our interviews with visual artists indicated that these object visualizers can use abstract mental images that are not based on previously seen real objects but, rather, represent nonexisting objects or a combination of features. Moreover, Miller (1996) cited several abstract artists (e.g., Jackson Pollock and Mark Rothko) who claimed that their paintings did not take themes from the real world but represented an abstract mixture of feelings and emotions with "vibrating strips of color." Conversely, spatial visualizers can use concrete images that represent objects at specific locations. Indeed, to transform most images properly, one needs to attend to the shape and appearance of the specific object (such as would occur if one is visualizing how best to pack luggage into a car's trunk or reconfigure the furniture in a room).

Neuroimaging may provide solid evidence that the two groups do, in fact, differ qualitatively in the type of imagery they prefer to use. If this hypothesis is correct, different patterns of brain activation should arise while the two groups perform visual-spatial problem-solving tasks. For instance, spatial visualizers should show more activation in areas associated with spatial representation (such as the posterior parietal lobes), whereas object visualizers should show more activation in areas associated with the representation of shapes (such as the inferior temporal lobes).

In closing, we note that if the present findings hold up over the course of further investigation, they will have direct implications for education, personnel selection, and professional training. If we are correct, it will not be useful to debate whether "high-imagery individuals" are more successful in learning than "low-imagery individuals," or whether imagery in general enhances or impairs performance on cognitive tasks. In order to make optimal use of the strengths of visual-spatial processing, we need to explore the relationships between different types of imagery and performance in various domains. Moreover, the question remains as to why people who are good at object imagery tend not to develop their spatial imagery ability and vice versa. One way to grapple with this issue is to discover whether people can be trained to use their less preferred type of imagery effectively.

\section{REFERENCES}

Aginsky, V., Harris, C., Rensink, R., \& Beusmans, J. (1997). Two strategies for learning a route in a driving simulator. Journal of Environmental Psychology, 17, 317-331.

ALESANDRINI, K. L. (1981). Pictorial-verbal and analytical-holistic learning strategies in science learning. Journal of Educational Psychology, 73, 358-368.

Ausburn, L. J., \& Ausburn, F. B. (1978). Cognitive styles: Some information and implications for instructional design. Educational Communications \& Technology Journal, 26, 337-354.

BADDELEY, A. [D.] (1992). Is working memory working? The Fifteenth Bartlett Lecture. Quarterly Journal of Experimental Psychology, 44A, 1-31. 
BARTlett, F. C. (1932). Remembering: A study in experimental and social psychology. Cambridge: Cambridge University Press.

Blajenkova, O., \& Kozhevnikov, M. (2002, November). Two types of imagers: The new self-report questionnaire. Paper presented at the 43rd Annual Meeting of the Psychonomic Society, Kansas City.

Campos, A., \& Suerio, E. (1993). Sex and age differences in visual imagery vividness. Journal of Mental Imagery, 17, 91-94.

Carpenter, P., Just, M. A., \& Shell, P. (1990). What one intelligence test measures: A theoretical account for the processing in the Raven Progressive Matrices test. Psychological Review, 97, 404-431.

Cohen J. D., MacWhinney B., Flatt M., \& Provost J. (1993). PsyScope: An interactive graphic system for designing and controlling experiments in the psychology laboratory using Macintosh computers. Behavior Research Methods, Instruments, \& Computers, 25, 257-271.

Collins, D. W., \& KimURA, D. (1997). A large sex difference on a twodimensional mental rotation task. Behavioral Neuroscience, 111, 845-849.

EDWARDS, J. E., \& WiLKINS, W. (1981). Verbalizer-visualizer questionnaire: Relationship with imagery and verbal-visual ability. Journal of Mental Imagery, 5, 137-142.

Ekstrom, R. B., French, J. W., \& Harman, H. H. (1976). Manual for kit of factor referenced cognitive tests. Princeton, NJ: Educational Testing Service.

Engle, R. W., KAne, M. J., \& Tuholski, S. W. (1999). Individual differences in working memory capacity and what they tell us about controlled attention, general fluid intelligence, and functions of the prefrontal cortex. In A. Miyake \& P. Shah (Eds.), Models of working memory: Mechanisms of active maintenance and executive control (pp. 102-135). Cambridge: Cambridge University Press.

Farah, M. J., Hammond, K. M., Levine, D. N., \& Calvanio, R. (1988). Visual and spatial mental imagery: Dissociable systems of representations. Cognitive Psychology, 20, 439-462.

Geary, D. C., Gilger, J. W., \& Elliot-Miller, B. (1992). Gender differences in three-dimensional mental rotation: A replication. Journal of Genetic Psychology, 153, 115-117.

GREen, K. E., \& Schroeder, D. H. (1990). Psychometric quality of the verbalizer-visualizer questionnaire as a measure of cognitive style. Psychological Reports, 66, 939-945.

Haxby, J. V., Grady, C. L., Horwitz, B., Ungerleider, L. G., Mishinin, M., Carson, R. E., Herscovitch, P., Schapiro, M. B., \& RAPOPORT, S. I. (1991). Dissociation of object and spatial visual processing pathways in human extrastriate cortex. Proceedings of the National Academy of Sciences, 88, 1621-1625.

HEGARTY, M., \& KoZHEVNIKOV, M. (1999). Types of visual-spatial representations and mathematical problem solving. Journal of Educational Psychology, 91, 684-689.

HuNT, E. (1975). Quote the raven? Nevermore! In L. W. Gregg (Ed.), Knowledge and cognition (pp. 129-158). Hillsdale, NJ: Erlbaum.

Kail, R., Carter, P., \& Pellegrino, J. (1979). The locus of sex differences in spatial ability. Perception \& Psychophysics, 26, 182-186.

KeEfe, J. W. (1979). Learning style: An overview. In J. W. Keefe (Ed.), Student learning styles: Diagnosing and prescribing programs (pp. 1-17). Reston, VA: National Association of Secondary School Principals.

Kirby, J., Moore, P., \& Shofield, N. (1988). Verbal and visual learning styles. Contemporary Educational Psychology, 13, 169-184.

KossLYN, S. M. (1994). Image and brain: The resolution of the imagery debate. Cambridge, MA: MIT Press.

Kosslyn, S. M., Ganis, G., \& Thompson, W. L. (2001). Neural foundations of imagery. Nature Reviews Neuroscience, 2, 635-642.

Kosslyn, S. M., \& KoenIG, O. (1992). Wet mind: The new cognitive neuroscience. New York: Free Press.

Kozhevnikov, M., Hegarty, M., \& Mayer, R. E. (2002). Revising the visualizer/verbalizer dimension: Evidence for two types of visualizers. Cognition \& Instruction, 20, 47-77.

KRUTETSKII, V. A. (1976). The psychology of mathematical abilities in schoolchildren. Chicago: University of Chicago Press.

Lean, C., \& Clements, M. A. (1981). Spatial ability, visual imagery, and mathematical performance. Educational Studies in Mathematics, 12, 267-299.

Levine, D. N., Warach, J., \& Farah, M. J. (1985). Two visual systems in mental imagery: Dissociation of "what" and "where" in imagery disorders due to bilateral posterior cerebral lesions. Neurology, $\mathbf{3 5}$, 1010-1018.

LoHMAN, D. F. (1988). Spatial abilities as traits, processes, and knowledge. In R. J. Sternberg (Ed.), Advances in the psychology of human intelligence (pp. 181-232). Hillsdale, NJ: Erlbaum.

MARKs, D. F. (1972). Visual imagery differences in the recall of pictures. British Journal of Psychology, 64, 17-24.

Messer, S. B. (1976). Reflection-impulsivity: A review. Psychological Bulletin, 83, 1026-1053.

MESSICK, S. (1976). Individuality in learning: Implications of cognitive style and creativity for human development. San Francisco: Jossey-Bass.

Messick, S. (1984). The nature of cognitive styles: Problems and promise in educational practice. Educational Psychologist, 19, 59-74.

Miller. A. (1996). Insights of genius: Imagery and creativity in science and art. New York: Springer-Verlag.

Milner, A. D., \& Goodale, M. A. (1995). The visual brain in action. Oxford: Oxford University Press.

Moses, B. E. (1980, April). The relationship between visual thinking tasks and problem-solving performance. Paper presented at the annual meeting of the American Education Research Association, Boston.

O'Reilly, R. C., Braver, T. S., \& Cohen, J. D. (1999). A biologically based computational model of working memory. In A. Miyake \& P. Shah (Eds.), Models of working memory: Mechanisms of active maintenance and executive control (pp. 102-135). Cambridge: Cambridge University Press.

Paivio, A. (1971). Imagery and verbal processes. New York: Holt, Rinehart \& Winston.

Paivio, A., \& Clark, J. M. (1991). Static versus dynamic imagery. In C. Cornoldi \& M. A. McDaniels (Eds.), Imagery and cognition (pp. 221-245). New York: Springer-Verlag.

Paivio, A., \& Harshman, R. A. (1983). Factor analysis of a questionnaire on imagery and verbal habits and skills. Canadian Journal of Psychology, 37, 461-483.

Poltrock, S. E., \& Agnoli, F. (1986). Are spatial visualization and visual imagery ability equivalent? In R. J. Sternberg (Ed.), Advances in the psychology of human intelligence (pp. 255-296). Hillsdale, NJ: Erlbaum.

Poltrock, S. E., \& Brown, P. (1984). Individual differences in spatial ability. Intelligence, 8, 93-138.

Prabhakaran, V., Smith, J. A. L., Desmond, J. E., Glover, G. H., \& GabriELI, J. D. E. (1997). Neural substrates of fluid reasoning: An fMRI study of neocortical activation during performance of the Raven's progressive matrices test. Cognitive Psychology, 33, 43-63.

Presmeg, N. C. (1986a). Visualization and mathematical giftedness. Educational Studies in Mathematics, 17, 297-311.

PrESMEG, N. C. (1986b). Visualization in high school mathematics. For the Learning of Mathematics, 63, 42-46.

Raven, J., Raven. J. C., \& Court, J. H. (1998). Manual for Raven's Progressive Matrices and Vocabulary Scales: Section 4, Advanced Progressive Matrices, Sets I and II, 1998 Edition. Oxford: Oxford Psychologists Press.

Richardson, A. (1977). Verbalizer-visualizer: A cognitive style dimension. Journal of Mental Imagery, 1, 109-126.

Richardson, J. T. E. (1999). Imagery. Hove, U.K.: Psychology Press.

Riding, R., \& CheEma, I. (1991). Cognitive styles: An overview and integration. Educational Psychology, 11, 193-215.

Rouw, R., Kosslyn, S., \& Hamel, R. (1997). Detecting high-level and low-level properties in visual images and visual percepts. Cognition, 63, 209-226.

Shepard, R. N., \& Metzler, J. (1971). Mental rotation of threedimensional objects. Science, 191, 952-954.

Snodgrass, J. G., \& VANDERWART, M. A. (1980). Standardized set of 260 pictures: Norms for name agreement, image agreement, familiarity, and visual complexity. Journal of Experimental Psychology, 6, 174-215.

Strosahl, K. D., \& Ascough, J. C. (1981). Clinical uses of mental imagery: Experimental foundations, theoretical misconceptions, and research issues. Psychological Bulletin, 89, 422-438.

Uhl, F., GoldenberG, G., LANG, W., \& Lindinger, G. (1990). Cerebral correlates of imagining colours, faces and a map: II. Negative cortical DC potentials. Neuropsychologia, 28, 81-93.

UNGERLEIDER, L. G., \& MishKIN, M. (1982). Two cortical visual systems. 
In D. J. Ingle, M. A. Goodale, \& R. J. W. Mansfield (Eds.), Analysis of visual behavior (pp. 549-586). Cambridge, MA: MIT Press.

WeCHSLER, D. (1999). WASI: Wechsler Abbreviated Scale of Intelligence. San Antonio: Psychological Corporation, Harcourt Brace.

Witkin, H. A., Moore, C. A., Goodenough, D. R., \& Cox, P. W. (1977). Field-dependent and field-independent cognitive styles and their implications. Review of Educational Research, 47, 1-64.

\section{NOTES}

1. The MPI has been extensively used in the mathematics education literature (Lean \& Clements, 1981; Moses, 1980; Presmeg, 1986a, 1986b), and the results consistently show that people can be reliably classified as visualizers or verbalizers according to this questionnaire.
This research found that the MPI has a high internal reliability and is largely independent of the sample being used.

2. Historically, a median split criterion has been used to distinguish between visualizers and verbalizers on different visualizer-verbalizer questionnaires. To be consistent with previous research on the visualizerverbalizer dimension, we defined visualizers and verbalizers in our studies in terms of a median split.

3. It is interesting to note that, according to the results of Kozhevnikov et al. (2002), neither visualizers nor verbalizers exhibit a bimodal distribution of verbal ability. These results suggest that verbal abilities, in contrast to mental imagery abilities, do not dissociate into two distinct groups.

4. All pairwise comparisons reported in the present article relied on Tukey's HSD test.

\section{APPENDIX A \\ Examples of Problems From the Visualizer-Verbalizer Cognitive Style Questionnaire}

Instructions:

\section{Part I}

Below are some problems to solve. Different people solve these problems in different ways. You may solve these problems any way you like. There is no right or wrong way of doing them. You may use the page to write down calculations or draw diagrams or if you prefer you may do the problems in your head. After you do the problems, we will ask you some questions about how you solved them.

Problem 1:

In an athletics race, Jim is four feet ahead of Tom and Peter is three feet behind Jim. How far is Peter ahead of Tom?

Problem 2:

At each of the two ends of a straight path a man planted a tree and then every 5 feet along the path he planted another tree. The length of the path is 15 feet. How many trees were planted?

Problem 3:

Jack, Paul, and Brian all have birthdays on January 1st, but Jack is one year older than Paul and Jack is three years younger than Brian. If Brian is 10 years old, how old is Paul?

Instructions:

\section{Part II}

Please indicate which (if any) of the methods described below you used for solving the problems of Part I. If you used several methods, indicate all methods you used. If you think that your method(s) for solving the problems was unlike any of those described in this part, describe your method, giving as many details as possible.

Problem 1:

_ I wrote mathematical expressions to represent the problem.

_ I solved the problem by imagining Jim, Peter, and Tom running in an athletics race.

- I solved the problem by drawing a diagram representing the relative position of Jim, Peter, and Tom in an athletics race,

_ I did not use any of the above methods

_ I attempted the problem in this way:

Problem 2:

_ I wrote mathematical expressions to represent the problem.

- I solved the problem by imagining the path and the trees, and then counting the trees in my mind.

_ I solved the problem by drawing a diagram representing the problem.

_ I did not use any of the above methods

_ I attempted the problem in this way:

Problem 3:

_ I wrote mathematical expressions to represent the problem.

_ I solved the problem by drawing a diagram representing the age of Jack, Paul, and Brian.

_ I solved the problem by drawing a chart or table representing the problem.

_ I did not use any of the above methods

_ I attempted the problem in this way: 


\section{APPENDIX B \\ Examples of Items From the Paper Folding Test}

In this test you are to imagine the folding and unfolding of pieces of paper [see Figure B1]. The figures on the left represent a square piece of paper being folded, and the last of these figures has one or two small circles drawn on it to show where the paper has been punched. One of the five figures on the right shows where the holes will be when the paper is unfolded. You are to decide which one of these figures is correct.
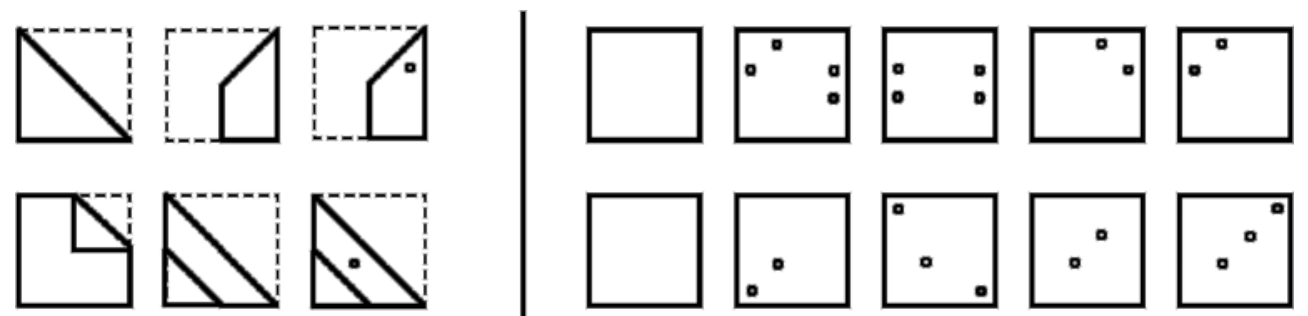

Figure B1. Example item from the Paper Folding Test.

(Manuscript received October 14, 2003;

revision accepted for publication July 22, 2004.) 